\title{
Comparação entre métodos de marcação da sonda de RFLP R2430E utilizada na seleção de cultivares de amendoim resistente à Meloidogyne arenaria
}

\author{
Comparison between methods of demarcation of probe of \\ RFLP R2430E used in the selection of resistance of peanut to \\ Meloidogyne arenaria
}

\author{
Valéria Carpentieri-Pípolo ${ }^{*}$; Maria Gallo-Meagher²; Don W. Dickson³; \\ Daniel W. Gorbet ${ }^{2}$; Maria de Lurdes Mendes'; Silvia Graciele Hülse de Souza ${ }^{5}$
}

\section{Resumo}

Neste trabalho foram comparados o método de hibridização com digoxigenina e o sistema de detecção por quimioluminescência com o método de marcação radioativa. Foram utilizados o cultivar suscetível Florunner e o resistente COAN. O DNA genômico foi isolado de folhas jovens e a análise de Southern blotting foi conduzida utilizando a sonda de RFLP R2430E. A detecção da sonda marcada com digoxigenina foi tão sensível quanto àquela marcada pela radioatividadade, porém com vantagens sobre o método radioativo. Por ser um método seguro e apresentar custos reduzidos, o método de marcação baseado na digoxigenina e detecção por quimioluminescência é altamente recomendável.

Palavras-chave: Detecção não radioativa, digoxigenina, marcadores moleculares

\begin{abstract}
This work had the aim of comparing the method of hybridization with digoxigenin and the chemiluminescent detection system with the method of radioactive labeled. The cultivars used were susceptible Florunner and resistant COAN. The genomic DNA was isolated from young leaves and Southern blotting analysis was conducted using RFLP probe R2430E. The detection of the probe labeled with digoxigenin was as sensitive as labeled by the radioactivity, however with advantages above the method radioactive. Due to be a safe method and to present reduced costs, the demarcation method based on the digoxigenin and chemiluminescent detection is highly recommendable.
\end{abstract}

Key words: Nonradiactive detection, digoxigenin, molecular markers

\footnotetext{
1 Professor Associado, Departamento de Agronomia, Universidade Estadual de Londrina - UEL, C.P: 6001, 86051-990, Londrina, PR, Brasil. E-mail: pipolo@uel.br.

2 Professor, University of Florida, IFAS, PO Box 110300, Gainesville, FL, 32611-0300, USA.

3 Professor, University of Florida, IFAS - 2212 Building 970, PO Box 110620, Gainesville, FL ,32611-0620, USA.

4 Biological Scientist, University of Florida, IFAS - 2212 Building 970, PO Box 110620, Gainesville, FL ,32611-0620, USA.

5 Engenheira Agrônoma, Pós-graduação em Agronomia, Departamento de Agronomia, UEL.Bolsista CNPq.

Autor para correspondência
} 


\section{Introdução}

O amendoim é atualmente uma das mais importantes oleaginosas cultivadas mundialmente, sendo a quarta mais produzida, perdendo apenas para a soja, o algodão e a canola. No Brasil, na safra de 2007/2008 a área plantada é de aproximadamente 116,6 mil hectares com produção média de 287,8 mil toneladas de grãos. No estado de São Paulo, que responde por $77 \%$ da produção do país e $70 \%$ da área plantada, a produção deste ano deve chegar a 220 mil toneladas (BRASIL, 2008). Problemas fitossanitários com nematóides do gênero Meloidogyne têm aumentado consideravelmente em todo mundo, causando reduções significativas na produção de amendoim (BURROW et al., 1996). As três principais espécies de Meloidogyne que vem limitando a produção de amendoim são $M$. arenaria (Neal) (Chitwood), M. hapla (Chitwood) e $M$. javanica (Chitwood), onde o $M$. arenaria tem causado danos crescentes, chegando a causar $12 \%$ de perdas de amendoim cultivado nos Estados Unidos e Índia (CARNEIRO; ALMEIDA; QUÉNÉHÉRVÉ, 2000; BAILEY, 2002). No estado da Geórgia (EUA) as perdas chegam a 16,4 milhões de dólares anualmente (CHU et al., 2007).

Considerando-se a acentuada redução da produtividade causada pelos nematóides, a facilidade de disseminação, alta persistência no solo e a inviabilidade de alguns métodos de controle, torna-se conveniente o uso de cultivares resistentes. Porém os programas tradicionais de melhoramento demandam considerável tempo e recursos, portanto a seleção de plantas para a resistência a nematóides assistida por marcadores moleculares pode otimizar um programa de melhoramento (GUIMARÃES et al., 2005).

\section{O RFLP (Restriction Fragment Lenght} Polymorphisms) foi a primeira técnica a ser utilizada para detectar variação em nível de DNA. O polimorfismo dos marcadores gerados ocorre devido à fragmentação do DNA através do uso de enzimas de restrição que é observado por hibridização com as seqüências homólogas de DNA marcadas com radioatividade ou compostos que desencadeiam uma luminescência (BOTSTEIN et al., 1980).

A marcação das sondas com fósforo radioativo $\left.{ }^{32} \mathrm{P}\right)$ tem sido utilizada com grande sucesso em estudos genéticos. Entretanto, a utilização de radioatividade requer instalações adequadas ao manuseio e dejeto do material radioativo. Por isso, novos métodos de hibridização têm sido sugeridos. O sistema de marcação não radioativo também conhecido por quimioluminescência, utiliza-se de nucleotídeos modificados contendo grupos, tais como digoxigenina (DIG) ou a biotina, que posteriormente são reconhecidos por conjugados anticorpos-enzimas. Nesse sistema o anticorpo se liga à molécula de digoxigenina na sonda, e a enzima conjugada catalisa uma reação de quimioluminescência, envolvendo um substrato, que ao ser degradado emite fótons de luz. O resultado é observado em autoradiografia após exposição com a membrana marcada (FERREIRA; GRATTAPAGLIA, 1998).

Portanto o objetivo deste trabalho foi comparar o método de hibridização com digoxigenina e detecção por quimioluminescência com o método de marcação radioativa aplicada na sonda de RFLP R2430E utilizada na seleção de cultivares de amendoim resistente ao Meloidogyne arenaria.

A fim de se comparar os dois métodos de marcação foi utilizado o cultivar suscetível Florunner e o resistente COAN. Para extração de DNA foram coletadas as folhas jovens e congeladas em $\mathrm{N}_{2}$ líquido e armazenadas a $-80^{\circ} \mathrm{C}$. O DNA genômico foi extraído de acordo com o protocolo de Rogers e Bendich (1985). Após a extração foi realizada a quantificação do DNA em espectrofotômetro e a concentração de DNA das amostras variaram de 30$50 \mu \mathrm{g}$.

Para a digestão de DNA, eletroforese e Southern blotting as amostras de DNA $(20 \mu \mathrm{g})$ foram digeridas overnight com a enzima de restrição EcoRI. Após completa digestão, o DNA foi submetido 
à eletroforese a $34 \mathrm{~V}$ por $16 \mathrm{~h}$ em gel de agarose $0,8 \%$ e transferido para a membrana Hybond $\mathrm{N}+$ por capilaridade (SOUTHERN, 1975) e fixado à membrana submetendo a UV por 3 min a $1600 \mathrm{~nm}$.

Para a marcação radioativa, hibridização e detecção, a sonda R2430E identificada em linhagens melhoradas de amendoin (CHOI et al.,1999) foi preparada através da reação em cadeia da polimerase (PCR) usando Taq polimerase de DNA. Cinqüenta ng da sonda de DNA foi marcada com $\alpha-\mathrm{P}^{32} \mathrm{dCTP}$ através da extensão do primer ao acaso (FEINBERG; VOGELTEIN, 1983). A préhibridização e hibridização ocorreram a $65^{\circ} \mathrm{C}$ com $7 \%$ SDS (Sodium Dodecyl Sulfate). As amostras foram lavadas três vezes por $20 \mathrm{~min}$ a $65^{\circ} \mathrm{C} \mathrm{com}$ 0.5X SSC (Standard Sodium Citrate) e 0.1\% SDS. Após a hibridização com as sondas, a membrana foi autoradiografada usando filme de raio-X exposta a $-70^{\circ} \mathrm{C}$ por 10 dias.

Para a marcação não-radioativa, hibridização e detecção, a sonda R2430E foi preparada através de PCR e a digoxigenina foi incorporada de acordo com o kit de marcação (Roche cat 1-093-657) seguindo as recomendações do fabricante. A préhibridização ocorreu em $7 \mathrm{~mL}$ de solução DIG Easy Hyb a $65^{\circ} \mathrm{C}$, e a hibridização ocorreu em 2,45 mL de solução DIG Easy $\mathrm{Hyb}$ a $70^{\circ} \mathrm{C}$ overnight $(6 \mathrm{a}$ $16 \mathrm{~h}$ ). A membrana foi lavada duas vezes em $2 \mathrm{X}$ SSC contendo $0,1 \%$ SDS em temperatura ambiente por $5 \mathrm{~min}$ e finalmente $0,5 \mathrm{X} \mathrm{SSC}$ contendo $0,1 \%$ SDS a $70^{\circ} \mathrm{C}$ duas vezes por $15 \mathrm{~min}$. O substrato quimioluminescente foi usado e os sinais foram visualizados em filme raio-X após $30 \mathrm{~min}$.

A sonda de RFLP R2430E utilizada para o teste mostrou estar associada a níveis altos de resistência ao nematóide $M$. arenaria. Os alelos de resistência e suscetibilidade foram bastante distintos e de fácil identificação (Figura 1). A sonda R2430E identificada em linhagens melhoradas de amendoin (CHOI et al., 1999) mostrou estar a uma distância de 4.2 centiMorgans (cM) do locus de resistência ao nematóide (CHURCH et al., 2000).

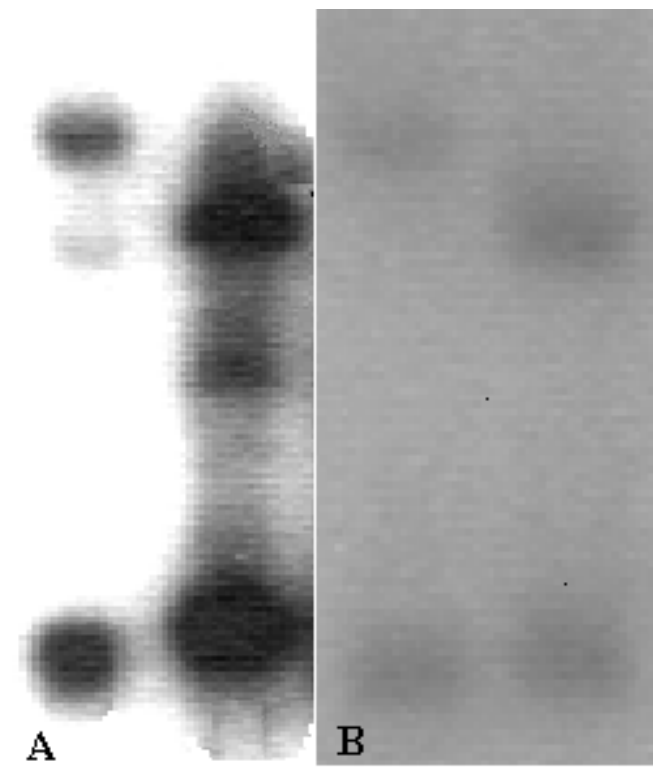

Figura 1. Locus de RFLP R2430E ligado à resistência ao Meloidogyne arenaria nos cultivares de amendoim COAN (resistente) e Florunner (suscetível), onde re S identificam os alelos de resistência e suscetibilidade, respectivamente. Figura 1A: Marcação com o isótopo radiativo ${ }^{32} \mathrm{P}$. Figura 1B: Detecção por quimioluminescência utilizando a digoxigenina como substrato.

Inicialmente foi utilizada a marcação com ${ }^{32} \mathrm{P}$, empregando essa técnica foi possível identificar a banda de resistência (Figura 1A) ao nematóide em indivíduos homozigotos. Isso mostra que esta técnica pode ser usada com grande eficiência em estudos genéticos podendo ser empregada com grande sucesso na identificação e seleção de genótipos superiores (CARPENTIERI-PÍPOLO et al., 2002). A hibridização com sondas radioativas é um método altamente específico e de amplo uso em detecção, porém especificamente, a marcação radioativa esbarra na necessidade de uma estrutura adequada de estocagem, manuseio e descarte, requer treinamento de pessoal e rigorosa precaução durante a manipulação e acima de tudo pode causar sérios problemas à saúde (HLOCH et al., 2001). Além disso, essas sondas devem ser utilizadas rapidamente devido à curta meia-vida. Considerando esses aspectos, métodos de marcação não-isótopos têm sido sugeridos como uma alternativa à substituição do método de marcação radiativa. 
A marcação não radioativa, empregada neste trabalho foi baseada na metodologia da digoxigenina que possibilitou a identificação da banda de resistência (Figura 1B) ao nematóide. No entanto a marcação utilizando o DIG não proporcionou a mesma qualidade e as intensidades das bandas foram menores que na marcação não radioativa. No que diz respeito à possibilidade de identificação dos genótipos, o método de hibridização com digoxigenina e detecção por quimioluminescência foi eficiente, embora a sensibilidade deste tenha sido baixa. A vantagem desse método é a longevidade da sonda, que pode ser usado por várias vezes sem a perda da atividade. $O$ tempo de exposição também é bastante curto variando de 5-30 min, sendo, portanto um método mais rápido, além do preparo e aplicação não diferir do método convencional, não sendo necessário o estabelecimento de técnicas novas (DIETZGEN et al., 1999). A disponibilidade das sondas de digoxigenina e a facilidade de armazenamento por um longo período contribuem para que haja uma diminuição dos custos. Associado a estas vantagens o sistema de marcação utilizando o DIG pode ser considerado uma técnica segura não oferecendo nenhum risco à saúde ou ao meio ambiente. A escolha de um ou outro tipo de marcação vai depender da viabilidade do laboratório, das características do material a ser utilizado, bem como dos objetivos do trabalho.

No presente trabalho, a sonda de RFLP R2430E é efetiva em identificar o alelo de resistência para $M$. arenaria, com alto nível de confiança. A detecção da sonda marcada com digoxigenina foi tão sensível quanto àquela marcada pela radioatividade, porém com vantagens sobre o método radioativo. Por ser um método seguro e apresentar custos reduzidos, o método de marcação baseado na digoxigenina e detecção por quimioluminescência é altamente recomendável.

\section{Referências}

BAILEY, J. Peanut disease management. In: NORTH Carolina peanut production guide. [S.1: s.n], 2002, Chapter 6.

BOTSTEIN, D.; WHITE, R. L.; SKOLNIC, M.; DAVIS, R. W. Construction of a genetic linkage map in man using restriction fragment length polymorphisms. American Journal of Human Genetics, Chicago, v. 32, n. 3, p. 314331,1980 .

BRASIL. Ministério da Agricultura, Pecuária e Abastecimento. CONAB: Companhia Nacional do Abastecimento. Disponível em: <http://www.conab.gov. br>. Acesso em: 16 jul. 2008.

BURROW, M. D.; SIMPSON, C. E.; PATERSON, A. H.; STARR, J. L. Identification of peanut (Arachis Hypogaea L.) RAPD markers diagnostic of root-knot nematode (Meloidogyne arenaria (Neal) Chitwood) resistence. Molecular Breeding, Belgium, v. 2, n. 4, p. 369-379, 1996.

CARNEIRO, R. M. D. G.; ALMEIDA, A. R. A.; QUÉNÉHÉRVÉ, P. Enzime phenotypes of Meloidogyne ssp. isolates. Nematology, Leiden, v. 2, n. 6, p. 645-654, 2000 .

CARPENTIERI-PÍPOLO, V.; DICKSON， D. W.; GALLO MEAGHER, M.; GORBET, D. W. Markerassisted selection in Screening peanut (Arachis hypogea L.) for resistance to the peanut root-knot nematode. In: THE FOURTH INTERNATIONAL CONGRESS OF NEMATOLOGY, 4., 2002, Tenerife. Proceedings... Tenerife : International Federation of Nematology Society, 2002. p. 227-227.

CHOI, K.; BUROW, M. D.; CHURCH, G. B.; PATERSON, A. H.; SIMPSON, C. E.; STARR, J. L. Genetics an mechanism of resistence to Meloygine arenaria in peanut germoplasm. Journal of Nematology, College. Park, v. 31, n. 3, p. 283-290, 1999.

CHU, Y.; HOLBROOK, C. C.; TIMPER, P.; OZIASAKINS, P. Development of a PCR-Based Molecular Marker to select for Nematode Resistance in Peanut. Crop Science, Madison, v. 47, n. 2, p. 841-847, 2007.

CHURCH, G. T.; SIMPSON, C. E.; BUROW, M. D.; PATERSON, A. H.; STARR, J. L. Use of RFLP marker for identification of individuals homozygous for resistance to Meloydogine arenaria in peanut. Nematology, New York, v. 5, n. 5, p. 575-585, 2000. 
DIETZGEN, R. G.; ABEDINA, M.; HIGGINS, C. M.; KARUNATRATNE, S.; VICKERS, J. Nonradioactive detection of transgenes in plant genomic southern blots. 1999. Disponível em: <https://www.rocheapplied-science.com/PROD_INF/BIOCHEMI/No1_99/ b199diet.htm>. Acesso em: 20 abr. 2005.

FEINBERG, A. P.; VOGELSTEIN, B. A technique for radiolabeling DNA restriction endonuclease fragments to high specific activity. Analytical Biochemistry, Washington, v. 132, n. 1, p. 6-13, 1983.

FERREIRA, M. E.; GRATTAPAGLIA, D. Introdução ao uso de marcadores moleculares em análise genética. 3.ed. Brasília: EMBRAPA/CENARGEM, 1998.

GUIMARÃES, P. M.; PROITE, K.; LEAL-BERTIOLI, S. C.; BERTIOLI, D. Análise in silico da expressão gênica diferencial de Arachis stenosperma inoculado com Meloidogyne arenaria. Boletim de Pesquisa e Desenvolvimento: Embrapa Recursos Genéticos e Biotecnologia, Brasília, v. 85, p. 1-25, 2005.
HLOCH, P.; HOFFMANN, K.; KRUCHEN, B.; RUEGER, B. The DIG System-a high sensitive substitute of radioactivity in northern blot analysis. 2001. Disponível em: $<$ https://www.roche-applied-science. com/PROD_INF/BIOCHEMI/No2_01/pdf/p24-25.pdf > Acesso em: 7 jan. 2006.

ROGERS, W.; BENDICH, A. J. Extration of DNA from milligram amounts of fresh, herbarium and mummified tissues. Plant Molecular Biology, Netherlands, v. 5, n. 2, p. 69-76, 1985.

SOUTHERN, E. M. Detection of specific sequences among DNA fragments separated by gel electrophoresis. Journal of Molecular Biology, California, v. 98, n. 3, p. 503-517, 1975. 
